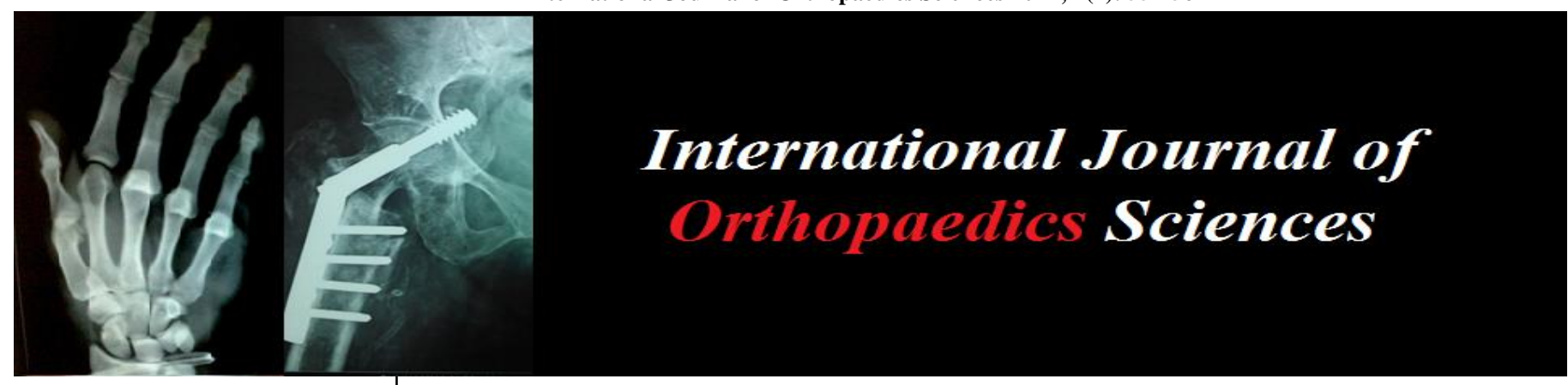

E-ISSN: 2395-1958

P-ISSN: 2706-6630

IJOS 2021; 7(1): 557-561

(C) 2021 IJOS

www.orthopaper.com

Received: 27-11-2020

Accepted: 30-12-2020

Dr. Deepak P Kaladagi

Associate Professor,

Orthopaedics, SNMC \& amp

HSK. Bagalkot. Karnataka.

India

Dr. Shivakumar B Kerakkanava

Associate Professor,

Orthopaedics, SNMC \& amp;

HSK. Bagalkot. Karnataka.

India

Dr. Nagesh B Sanakal

Senior Resident, Orthopaedics,

SNMC \& amp; HSK. Bagalkot.

Karnataka. India

Dr. Pundaleekappa S Kaladagi Professor, Orthopaedics, SNMC \& amp; HSK. Bagalkot.

Karnataka. India

Dr. Praveenkumar A Hongal Junior Resident, Orthopaedics, SNMC \& amp; HSK. Bagalkot. Karnataka. India
Corresponding Author:

Dr. Shivakumar B Kerakkanavar Associate Professor,

Orthopaedics, SNMC \& amp;

HSK. Bagalkot. Karnataka.

India

\section{Study the complications of displaced fracture neck of femur in elderly patients treated with cemented bipolar hemiarthroplasty}

\author{
Dr. Deepak P Kaladagi, Dr. Shivakumar B Kerakkanavar, Dr. Nagesh B \\ Sanakal, Dr. Pundaleekappa S Kaladagi and Dr. Praveenkumar A Hongal
}

DOI: https://doi.org/10.22271/ortho.2021.v7.i1i.2542

\begin{abstract}
Aims and Objectives: To evaluate the complications of displaced fracture neck of femur in elderly treated with cemented bipolar hemiarthroplasty.

Material and Methods: The present research was a prospective study of 44 cases of displaced femur bone fractures admitted to S.N.M.C. and H.S.K. Hospital in Bagalkot between October 2017 and October 2019. Cases were selected on the basis of inclusion and exclusion criteria. Medically unsuitable and nonoperative patients have been removed from the study. Cases have been treated with cemented bipolar hemiarthroplasty.

Results: In our 44 cases, there were 30 females and 14 males, with a median age of 92 years, a minimum age of 65 years and an average age of 72.72 years. There was a small predominance of left-sided fractures (54.55 per cent) relative to the right-sided fractures. The average score for the final 1 year follow-up was 86.75 per cent (maximum score of 95 and a minimum score of 66). Patients progressed well with few complications such as a difference in limb length, with $36.36 \%$ of patients ranging from 1 to $1.5 \mathrm{~cm}$ in length.

Conclusion: Cemented bipolar hemiarthroplasty for fractures of the femoral neck offers a greater range of movement, relief from pain and a quicker return to unassisted operation with a reasonable complication rate. End-to-end functional outcomes depend on the age of the patient, underlying comorbidity, and optimum post-operative recovery. Long-term results using bipolar hemiarthroplasty need more study in a larger community for a longer period of time. Bipolar prosthesis is a safe option in the treatment of fractures of the femur in elderly patients with serious rehabilitation, despite having multiple comorbidities.
\end{abstract}

Keywords: Bipolar hemiarthroplasty, Fracture neck femur, Elderly patients

\section{Introduction}

Fracture of the femur is the leading cause of hospital admission to the elderly age group. The number of such admissions is on the rise due to increased lifespan, osteoporosis and sedentary habits. A conservative type of treatment is not suitable, as it results in non-union with unstable hip movements and restriction of hip movements, as well as complications of prolonged immobilisation such as bedsores, DVT and respiratory infections. Multiple internal fastening solutions (screws, dynamic hip screw plates or blade plates) and Hemi/total hip arthroplasty are possible.

Hemiarthroplasty is a time-tested surgical procedure used to treat displaced femoral neck fractures in elderly patients. Satisfactory outcomes have been obtained in terms of pain relief, early return to pre-derived life, decreased mortality and morbidity relative to osteosynthesis ${ }^{[1-}$ 3].

Bipolar hemiarthroplasty, therefore, appears to be the best cure for the acute fracture of the elderly's spine. However, there is no evidence available on its long-term consequences. Some scholars have also expressed doubts as to the degree of internal motion on long-term use, thus calling into question its effectiveness ${ }^{[4]}$.

Cemented prostheses have been routinely used as the bone density of most elderly patients deteriorates and most of them have a large proximal medullar canal diameter. Bone cement 
would therefore provide immediate cohesion between bone and prosthesis and allow for maximum weight-bearing ${ }^{[5]}$.

Compared with uncemented bipolar hemiarthroplasty, the use of cemented bipolar hemiarthroplasty has more advantages, such as more stable fixation, particularly in elderly (osteoporotic) patients who promote early mobilisation and lower chances of thigh pain ${ }^{[6]}$.

In our study, 44 patients with an average age of 72.72 years with a female predominance of broken femur neck were treated with cemented bipolar hemiarthroplasty. Intraoperative and postoperative complications have been reported.

\section{Materials and Methods}

This is a two-year analysis from October 2017 to October 2019. Traumatic, Displaced fractures of the neck of the femur in elderly patients (> 65 years of age) presenting with $S$. Nijalingappa Medical College and H.S.K Hospital, Bagalkot, were included in the study.

\section{Data Collection}

Data were collected on the basis of a detailed history, clinical and radiological evaluation of the patient. Postoperative assessment was done both clinically and radiologically. Out of the 44 cases, all patients were eligible for follow-up until one year, which was considered a basic pre-requisite for study inclusion.

\section{Inclusion criteria}

1. Displaced fracture neck of femur in more than 65 years of age.

2. Independent walking ability.

3. Independent living condition.

4. Absence of severe cognitive function.

\section{Exclusion criteria}

1. Osteoarthritis of the hip

2. Rheumatoid arthritis

3. Mental illness

4. Drug abuse

5. Alcohol abuse

6. Pathological fracture

\section{Methodology}

Once the patient was admitted to the hospital, clinical and radiological investigations were carried out and all the critical details of those who met the inclusion criteria was reported in the proforma prepared for this review.

\section{Statistical analysis}

The data collected was entered and analysed in the MS Excel sheet. Percentage and proportions were used to determine the functional outcome of the displaced fracture of the femur in elderly patients treated with cemented bipolar prosthesis by Updated Harris Hip Score.

\section{Results}

Table 1: Age distribution

\begin{tabular}{|c|c|c|}
\hline Age & Frequency & Percentage (\%) \\
\hline 65-74 Year & 30 & 68.18 \\
\hline 75-84 Year & 13 & 29.54 \\
\hline >85 Year & 01 & 02.28 \\
\hline Total & 44 & 100 \\
\hline
\end{tabular}

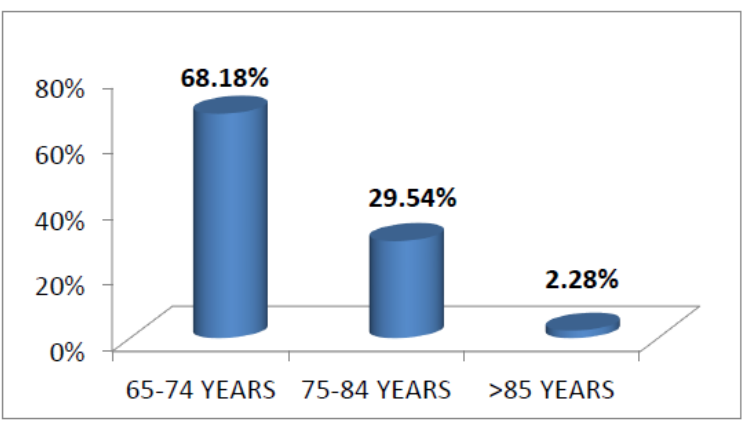

Fig 1: Age distribution

In this study age between $65-74$ years patients were more, the average age among the patients is of 72.72 years. The youngest patient in the study was 65 years and the oldest was 92 years.

Table 2: Sex distribution

\begin{tabular}{|c|c|c|}
\hline Sex & Frequency & Percentage (\%) \\
\hline Male & 14 & 31.82 \\
\hline Female & 30 & 68.18 \\
\hline Total & 44 & 100 \\
\hline
\end{tabular}

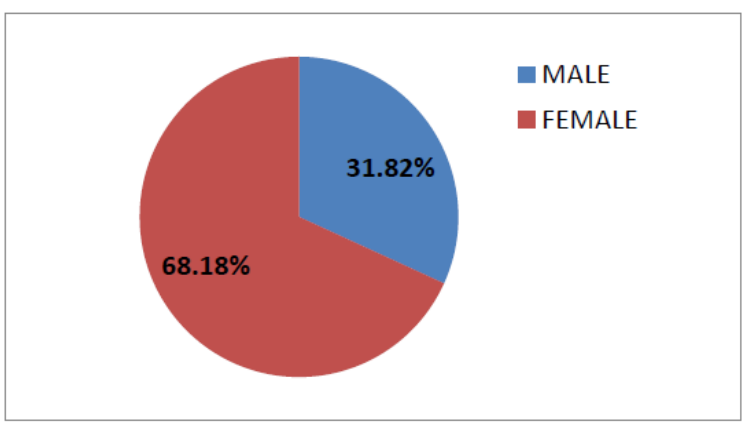

Fig 2: Sex distribution

Table and Figure 2 show the sex distribution pattern of the study patients. Most of the patients were found to be women $68.18 \%$ (30 patients).

Table 3: Laterality

\begin{tabular}{|c|c|c|}
\hline Side & Frequency & Percentage (\%) \\
\hline Right & 20 & 45.45 \\
\hline Left & 24 & 54.55 \\
\hline Total & 44 & 100 \\
\hline
\end{tabular}

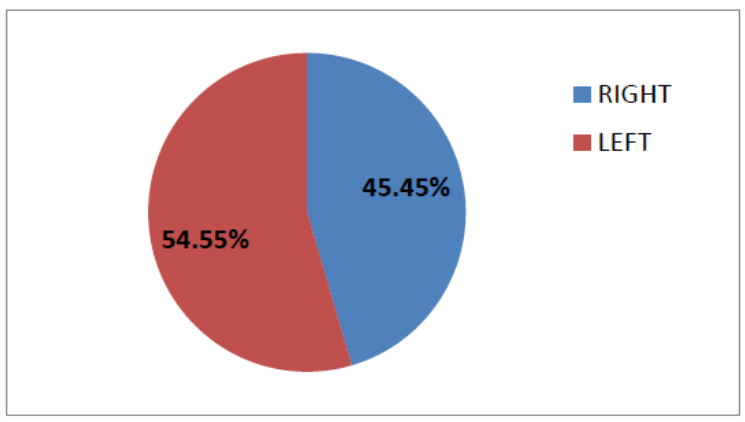

Fig 3: Laterality

Table and Figure 3 indicate the lateral trend of all left-side patients more affected by the study with 54.55 percent. 
Table 4: Mode of injury

\begin{tabular}{|c|c|c|}
\hline Mode of Injury & Frequency & Percentage (\%) \\
\hline Slipping & 37 & 84.10 \\
\hline Fall from Height & 07 & 15.90 \\
\hline Total & 44 & 100 \\
\hline
\end{tabular}

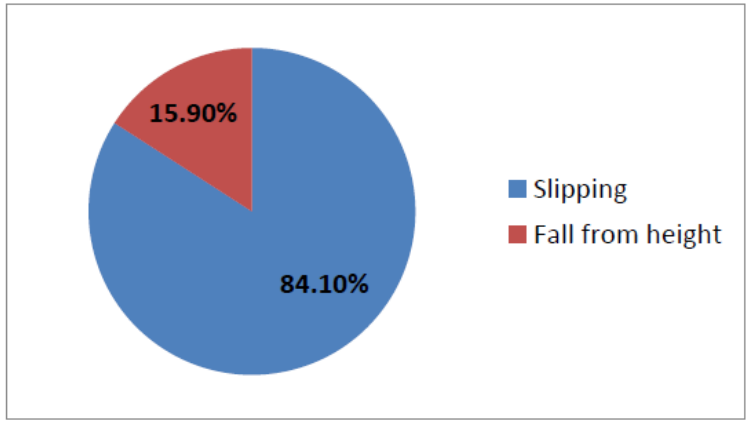

Fig 4: Mode of injury

Table and Figure 4 show Most of the patients' sustained fractures just because of trivial trauma, i.e. Slipping $84.10 \%$.

Table 5: Garden's classification

\begin{tabular}{|c|c|c|}
\hline Garden's Type & Frequency & Percentage (\%) \\
\hline Type-1 & 00 & 00 \\
\hline Type-2 & 00 & 00 \\
\hline Type-3 & 25 & 56.82 \\
\hline Type-4 & 19 & 43.18 \\
\hline Total & 44 & 100 \\
\hline
\end{tabular}

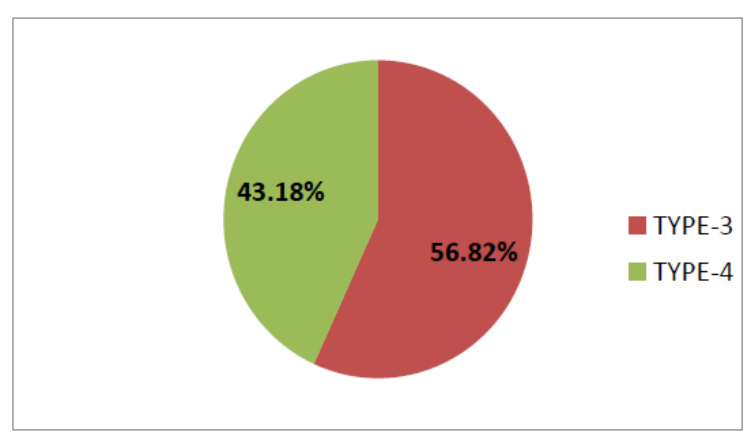

Fig 5: Garden's classification

Table and Figure 5 shows most of the patients i.e., $56.82 \%$ had type 3 fractures.

Table 6: Singh's grade of proximal femur

\begin{tabular}{|c|c|c|}
\hline Singh's Index & Frequency & Percentage (\%) \\
\hline Grade-3 & 14 & 31.82 \\
\hline Grade-4 & 16 & 36.36 \\
\hline Grade-5 & 14 & 31.82 \\
\hline Total & 44 & 100 \\
\hline
\end{tabular}

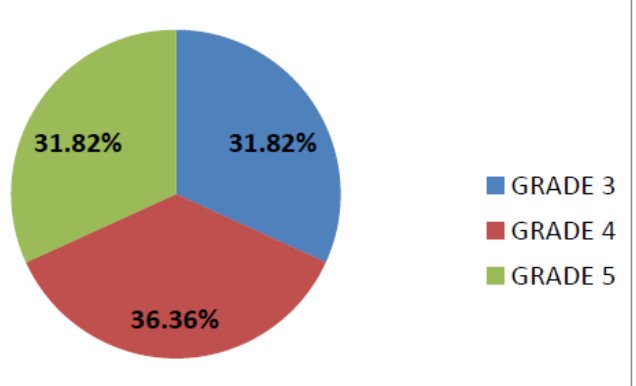

Table and Figure 6 shows grade 4 trabecular pattern of the proximal femur is seen in most of the cases in our study i.e., $36.36 \%$.

Table 7: Dorr's type

\begin{tabular}{|c|c|c|}
\hline Dorr's Type & Frequency & Percentage (\%) \\
\hline Type-B & 24 & 54.55 \\
\hline Type-C & 20 & 45.45 \\
\hline Total & 44 & 100 \\
\hline
\end{tabular}

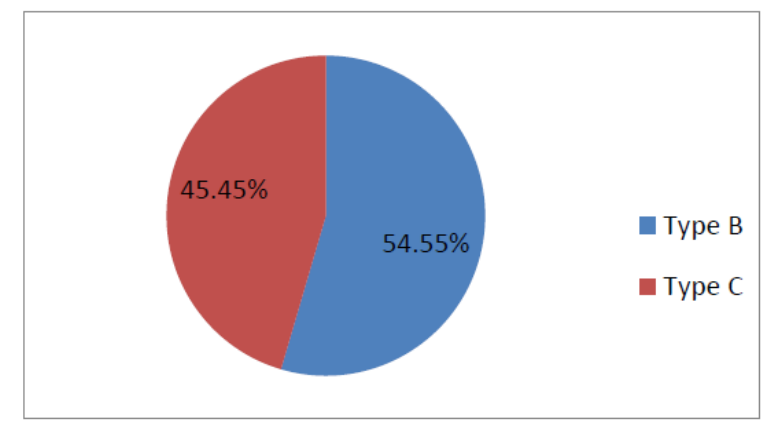

Fig 7: Dorr's type

In our study, the majority of femoral canal diameter described under Dorr's type, has type B i.e, 54.55\%.

Table 8: Distribution of femoral canal diameter between male and female

\begin{tabular}{|c|c|c|c|c|c|}
\hline \multicolumn{2}{|c|}{$\begin{array}{c}\text { Dorr's Type- } \\
\text { B }\end{array}$} & $\begin{array}{c}\text { Percentage } \\
(\boldsymbol{\%})\end{array}$ & \multicolumn{2}{c|}{$\begin{array}{c}\text { Dorr's Type- } \\
\text { C }\end{array}$} & $\begin{array}{c}\text { Percentage } \\
(\boldsymbol{\%})\end{array}$ \\
\hline Male & 08 & 33.33 & Male & 06 & 30 \\
\hline Female & 16 & 66.67 & Female & 14 & 70 \\
\hline Total & 24 & 100 & Total & 20 & 100 \\
\hline
\end{tabular}

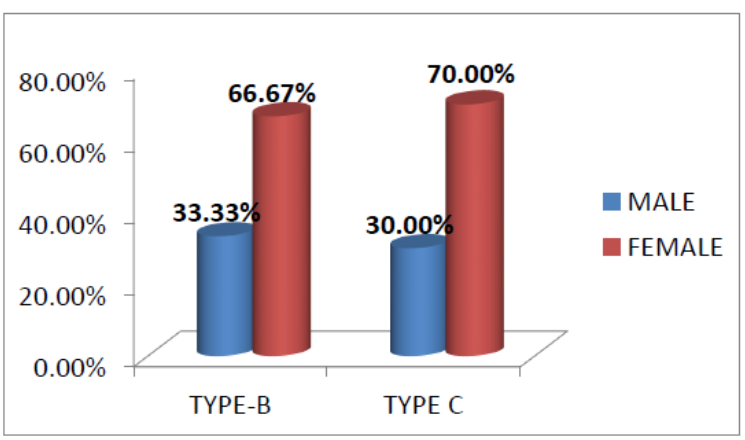

Fig 8: Distribution of femoral canal diameter between male and female

Table and Figure 8 show female femoral canal diameter is more i.e., $66.67 \%$ Dorr's-B and 70\% Dorr's-C compare to males in our study.

Table 9: Complications of surgery - Limb length discrepancy

\begin{tabular}{|c|c|c|}
\hline LLD & Frequency & Percentage (\%) \\
\hline Nil $-1 \mathrm{~cm}$ & 27 & 61.36 \\
\hline $1-1.5 \mathrm{~cm}$ & 16 & 36.36 \\
\hline$>1.5 \mathrm{~cm}$ & 1 & 02.28 \\
\hline Total & 44 & 100 \\
\hline
\end{tabular}

Fig 6: Grade 


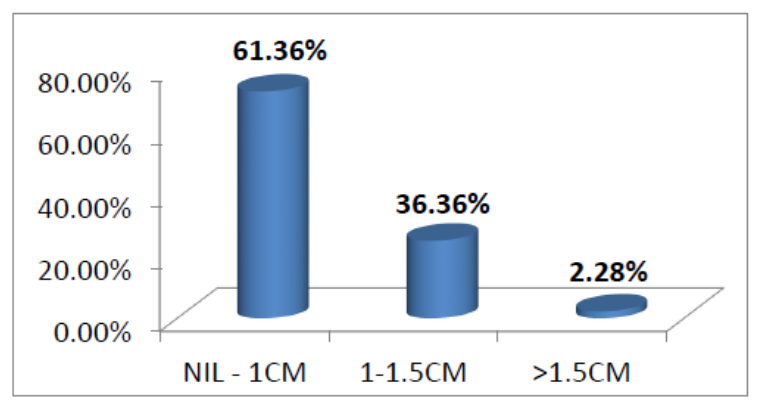

Fig 9: Complications of surgery - Limb length discrepancy

Table and Figure 8 indicate that the majority of patients in our study have no different length of limb than length of $1-1.5 \mathrm{~cm}$ in 36.36 percent of patients.

Table 10: Co-morbidities associated

\begin{tabular}{|c|c|c|}
\hline Co-morbidities & Frequency & Percentage (\%) \\
\hline Nil & 28 & 63.64 \\
\hline HTN & 04 & 09.09 \\
\hline DM & 03 & 06.82 \\
\hline DM and HTN & 06 & 13.63 \\
\hline IHD & 03 & 06.82 \\
\hline Total & 44 & 100 \\
\hline
\end{tabular}

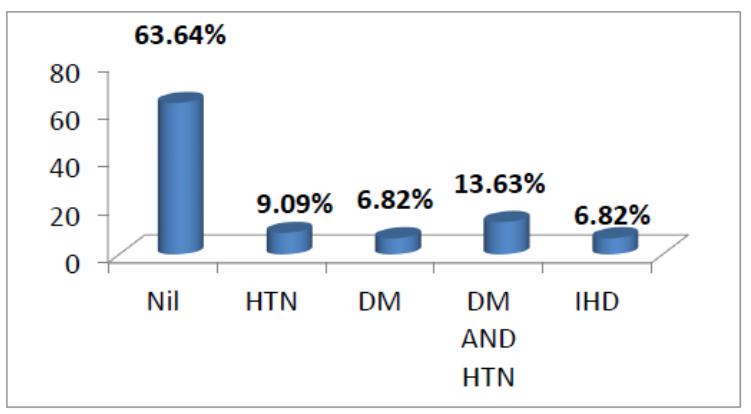

Fig 10: Co-morbidities associated

Among the 44 patients in this sample, 63.64 per cent of patients had cardio-respiratory problems, diabetic status, and others within normal limits. 13.63 percent of patients had hypertension and diabetes. 9.09 per cent and 6.82 per cent had hypertension and diabetes, respectively. 6.82 percent of patients have ischaemic heart disease.

\section{Discussion}

The goal of surgical reconstruction in the broken neck of the femur is an early return to everyday activities and mobilization. This refers in particular to the elderly age group, where problems due to long periods of bedridden and immobilization have to be avoided.

The mean age of the patients in this sample was 72.72 years, the youngest 65 years and the oldest 92 years. Age distribution is an important factor in the management of hip fractures to be prepared for prosthesis collection and use of cement.

As in other normal studies, the present research also included a higher number of females, i.e. 68.18 percent who had a broken femur neck compared to the male population of 31.82 percent. Elderly females are more likely to fracture the neck of the femur due to osteoporosis (postmenopausal condition) [7]

The majority of our patients in the study were 84.10 percent injured due to trivial trauma such as tripping or falling. This is a very common condition in the elderly community, where vision impairment and lack of neuromuscular function are problematic. Many of these incidents can be listed as indirect trauma. 15.90 percent of patients were injured due to a drop in height.

In our study, most patients had a fracture of the neck of the femur. The majority of patients (25) had a Type III Garden fracture (56.82 percent) and 19 patients (43.18 percent) had a Type IV Garden fracture. Even in a comparative analysis by H. Krishnan, "Among the effects of Cemented and Uncemented bipolar prosthesis, 29 patients had Garden IV, while 5 patients had a Garden III fracture." [8]. However, there are no major improvements in the outcomes of the forms of fracture and displacement ${ }^{[8]}$.

Among the 44 patients in this sample, 63.64 per cent of patients had cardio-respiratory problems, diabetic status, and others within normal limits. 13.63 percent of patients had both hypertension and diabetes, 9.09 percent had hypertension and 6.82 percent had diabetes. 6.82 percent of patients have ischaemic heart disease. In three patients with diabetes whose sugar levels were not controlled by oral hypoglycaemics, we began injection of insulin to regulate the preoperative level of blood sugar. As a result, the operation has been postponed for 7 days. Six patients with both hypertension and diabetes had high blood pressure and diabetes under control; thus, surgery was postponed for 4 days. Three patients with IHD were taking tab ecospirin, it was stopped 5 days before surgery.

Postoperative rehabilitation of patients is greatly affected by the presence of the above-mentioned comorbidities. 54 Patients had to wait an average of 6 days for surgery for a couple of days. It also had an effect on the final functional outcome of the operation. Koval et al. ${ }^{[9]}$ and Bath ${ }^{[10]}$ have made similar observations.

Most of the surgery was done between 90 and 120 minutes after the start of the operation. Haidukewych, et al. [11] reported "A similar period of treatment. The duration of the process had some effect on the final function. Most of our patients were mobilized in bed on the first day of surgery and weighed as tolerated within 72 hours of surgery. Delay if this was due to medical reasons at all."

One patient with hypertension and one patient with IHD developed hypotension during cementation and was treated accordingly. Literature indicates that intraoperative deaths (cardiac arrest) during hip arthroplasty occur rarely and have been associated with bone cement ${ }^{[12]}$. Patients with significant underlying cardiovascular disease are more likely to encounter this problem ${ }^{[13]}$. The hemodynamic effects of medullary fat embolism during the cement pressurization process, rather than the toxic effects of cement itself, cause Bone Cement Implantation Syndrome ${ }^{[12]}$.

Limb length variations were observed in 17 postoperative patients (38.64 percent), of which 16 patients had lengthening between $1-1.5 \mathrm{~cm}$ and 1 patient had $2 \mathrm{~cm}$, possibly due to less calcar resection.

Nottage, et al. ${ }^{[14]}$ reported that "One patient had mild grade fever on the second day of surgery, the wound was examined and there were no signs of infection at the surgical site. A superficial infection in the form of a wound dehiscence was seen in a patient who was a diabetic. It was controlled by debridement and secondary saturation with sufficient control of diabetic status and appropriate antibiotics based on culturesensitivity findings. The infection was resolved without any sequelae, and there was no delayed reactivation of the infection. The infection rate of $3.9 \%$ after bipolar hemiarthroplasty."

For all patient administration of I.V. Antibiotics have been 
followed for 5 days and all aseptic steps have been taken for dressing. Normal physiotherapy, such as static quadriceps exercises, ankle pump exercises, side sitting, knee movements, and other helpful drugs.

Patients were permitted to stand on the second day and began walking with a walker and full weight on the operated leg for 72 hours depending on the tolerability of the patient's pain. Both patients were able to walk with a walker and with the full weight of the discharge. Marya SKS et al. study shows that "The postoperative protocol for patients with cemented implants (bipolar or complete hip) includes optimal weightbearing as soon as possible (depending on the patient's capacity to be supported) and successful hip and knee exercises that provide positive results and restore the premorbid status of patients." However, in the case of uncemented bipolar prosthesis, the weight of the prosthesis was delayed and the postoperative procedure differed, i.e. patients with cementless implants (bipolar or complete hips) were mobilized for a period of three weeks, partially weightbearing for the following nine weeks and then permitted maximum weight-bearing without support ${ }^{[7]}$.

In a study conducted by Marya SKS et al. state that "With 84 patients, few complications arose, such as one case of deep infection, two cases of DVT but no fatal PE, three cases of dislocation (all managed by closed reduction and postreduction hip abduction bracing for six to eight weeks), two cases of thigh pain (all in the cementless subgroup), five patients developed superficial bedsores (which were also cured)." [7] There were no early and late postoperative complications such as DVT, thigh pain, loosening, dislocation, deterioration, secondary osteoarthritis, protrusio acetabuli, or periprosthetic fracture.

\section{Conclusion}

Cemented bipolar hemiarthroplasty for fractures of the femoral neck offers a greater range of movement, relief from pain and a quicker return to unassisted operation with a reasonable complication rate. End-to-end functional outcomes depend on the age of the patient, underlying co-morbidity, and optimum post-operative recovery. Long-term results using bipolar hemiarthroplasty need more study in a larger community for a longer period of time. Hypotension is usually seen in patients with systemic co-morbidity. Extension of not more than $2 \mathrm{~cm}$ is a common complication. Bipolar hemiarthroplasty for unstable hip fractures in the elderly has excellent results with early mobilization and minimal complications.

\section{References}

1. Yau WP, Chiu KY. Critical radiological analysis after Austin Moore hemiarthroplasty. Injury 2004;35(10):1020-24. DOI: 10.1016/j.injury.2003.08.016. [PubMed]

2. Wachtl SW, Jakob RP, Gautier E. Ten-year patient, and prosthesis survival after unipolar hip hemiarthroplasty in female patients over 70 years old. J Arthroplasty 2003;18(5):587-91. DOI: 10.1016/s0883-5403(03)002079. [PubMed]

3. Clayer M, Bruckner J. The outcome of Austin-Moore hemiarthroplasty for fracture of the femoral neck. Am J Orthop (Belle Mead NJ) 1997;26(10):681-84. [PubMed]

4. Schneppendahl J, Grassmann JP, Petrov V, Böttner F, Körbl B, Hakimi M et al. Decreasing mortality after femoral neck fracture treated with bipolar hemiarthroplasty during the last twenty years. Int Orthop.
2012;36(10):2021-26. DOI: 10.1007/s00264-012-1600-z. Epub 2012 Jun 28. [PubMed]

5. Langslet E, Frihagen F, Opland V, Madsen JE, Nordsletten L, Figved W. Cemented versus uncemented hemiarthroplasty for displaced femoral neck fractures: 5year followup of a randomized trial. Clin Orthop Relat Res 2014;472(4):1291-99. DOI: 10.1007/s11999-0133308-9. Epub 2013 Oct 1. [PubMed]

6. LaBelle LW, Colwill JC, Swanson AB. Bateman bipolar hip arthroplasty for femoral neck fractures. A five- to tenyear follow-up study. Clin Orthop Relat Res 1990;(251):20-5. [PubMed]

7. Marya SK, Thukral R, Singh C. Prosthetic replacement in femoral neck fracture in the elderly: results and review of the literature. Indian J Orthop 2008;42(1):61-7. DOI: 10.4103/0019-5413.38583. [PubMed]

8. Krishnan H, Yoon TR, Park KS. Bipolar Hemiarthroplasty in patients presenting with displaced intracapsular femoral neck fractures- A comparison of cemented and uncemented prosthesis placement. Malaysian Orthopaedic Journal 2010;4(1):26-31.

9. Koval KJ, Zuckerman JD. Functional recovery after fracture of the hip. J Bone Joint Surg Am 1994;76(5):751-58.

DOI: 10.2106/00004623-199405000-00018. [PubMed]

10. Bath R. Problems in the treatment of femoral neck fractures. Proceedings of the Royal Society of Medicine 1975;63:1120-28.

11. Haidukewych GJ, Israel TA, Berry DJ. Long-term survivorship of cemented bipolar hemiarthroplasty for fracture of the femoral neck. Clin Orthop Relat Res 2002;(403):118-26. DOI: 10.1097/00003086-20021000000019. [PubMed]

12. Parvizi J, Holiday AD, Ereth MH, Lewallen DG. The Frank Stinchfield Award. Sudden death during primary hip arthroplasty. Clin Orthop Relat Res 1999;(369):3948. DOI: 10.1097/00003086-199912000-00005. [PubMed]

13. Zofka P. Bipolární endoprotéza kycelního kloubu [Bipolar hip hemiarthroplasty]. Acta Chir Orthop Traumatol Cech 2007;74(2):99-104. [PubMed]

14. Nottage WM, McMaster WC. Comparison of bipolar implants with fixed-neck prostheses in femoral-neck fractures. Clin Orthop Relat Res 1990;(251):38-43. [PubMed] 